\author{
Е.А. Наугольных \\ Пермская государственная \\ фрармацевтическая академия, Пермь, Россия

\section{ОККАЗИОНАЛЬНОЕ СЛОВО СКВОЗЬ ПРИЗМУ КОНТЕКСТА: СПЕЦИФИКА ПЕРЕВОДА}

Анализируются формально-содержательное взаимодействие окказиональной единицы и контекста, а также проблемы межъязыковой передачи индивидуально-авторских новообразований. Материалом для анализа послужили роман Дж. Джойса «Улисс» и его четыре перевода на немецкий и русский языки. Проанализированы три типа взаимодействия контекста , в том числе относительная автономия окказиональной единицы, с одной стороны, и ее полноценное участие в поддержании и организации динамического развертывания текстового целого, с другой стороны. Обнаружено, что в романе «Улисс» контекст почти всегда в определенной степени является фактором, влияющим на понимание окказиональной единицы, а следовательно, и на его правильную передачу в языке перевода. Значение окказионализма зачастую предусматривает активацию различных связей с вербальным контекстом, а также апелляцию к фоновым знаниям. Применение разных переводческих приемов при передаче одного и того же окказионализма нередко обусловлено широкой амплитудой интерпретации окказионализмов Дж. Джойса, что максимально затрудняет работу переводчиков в поиске межъязыковых соответствий. Выявлена также некоторая зависимость переводимости исследованных единиц от структурной близости языка оригинала и языков перевода.

Ключевые слова: окказиональное слово, контекст, формально-содержательные связи, окружение, языковая игра, словообразовательная модель, переводимость.

\title{
E.A. Naugolnykh
}

Perm State Pharmaceutical Academy, Perm, Russia

\section{OCCASIONIALISMS IN CONTEXT: TRANSLATION CHALLENGES}

The paper is devoted to studying form-and-content interaction of occasionalisms and context, as well as the challenges of their translation into other languages. For this aim the novel of James Joyce "Ulysses" and its four full versions in German and Russian languages are investigated. Three types of context interactions are analyzed, starting with lexical unit relative autonomy from the context and ending with its crucial role in maintaining and dynamic building up of the whole text. Most occasionalisms in Ulysses are found to be strongly context-dependent - the fact that influences their comprehension and translation into other languages. Decoding their meaning often involves activation of various links with the verbal context, as well as appeal to the background knowledge. The use of various translation methods when rendering the same occasionalisms is frequently due to the broad interpretation of investigated unit. This highly complicates the hunting of translators for Russian and German equivalents. Some regularity in the choice of translation method, particularly its dependence on the structural similarities of the target and source languages is revealed.

Keywords: occasionalism, context, formal-and-content links, surrounding, language game, word-formation model, translatability. 
Будучи результатом творческой активности писателя, намеренные языковые девиации всегда вызывали интерес исследователей-лингвистов. Именно целенаправленное нарушение семантико-стилистических, словообразовательных, морфологических и синтаксических норм языка позволяет добиться особой экспрессии и, как следствие, необходимого художественного эффекта.

Перевод художественного текста оценивается, прежде всего, по его литературным достоинствам и по его соответствию стилистическим особенностям текста подлинника [1, с. 153]. Проблема межъязыковой передачи языковых аномалий в действительности затрагивает область непереводимого в переводе, ведь далеко не каждый язык позволяет адекватно транслировать разноуровневые девиации, предложенные автором, особенно когда речь идет о текстах, созданных писателями модернистами и постмодернистами, такими как Дж. Джойс. Его роман «Улисс» представил собой нечто абсолютно новое для времени, когда он появился. Как верно подметил Дж. Р. Олдингтон, в нем «Джойс смело обращается со словами, но творит совершенно удивительные вещи» [2, с. 15]. Поэтому при переводе таких произведений часто приходится прибегать к совершенно иным языковым средствам.

Обладая относительно небольшой формальной структурой, окказиональное слово в содержательном плане являет собой концентрированный сгусток смысла. В отличие от простого немотивированного слова, у которого значения содержательны, а внутренняя форма как бы сведена к семантическому нулю, у окказионального слова содержательны и значение, и внутренняя форма. Очевидно, что значение окказионального слова складывается не только из смысла его составных частей, но и зависит от контекста. Естественно, взаимодействие окказионализма с контекстом может иметь разную степень силы.

О.Г. Баталов выделил следующие три типа формально-содержатель-ного взаимодействия окказиональной единицы и контекста: 1) отсутствие очевидных формально-содержательных связей окказионального слова и контекста; 2) контекст носит доминирующий характер при моделировании семантики образованного слова; 3) отношение взаимозависимости нового слова с контекстом или текстом в целом [3]. Цель данной статьи - проанализировать отобранные окказиональные слова в романе Дж. Джойса «Улисс», основываясь на приведенной выше классификации, и проверить возможность их трансляции на русский и немецкий языки. Были исследованы четыре версии романа: два перевода на немецкий язык (первый вариант Г. Гойерта и вторая более поздняя версия, сделанная Г. Волльшлегером), а также два перевода на русский язык (первая полная версия романа, предложенная В. Хинкисом, С. Хоружий и последняя современная версия С. Махова).

К первому типу формально-содержательного взаимодействия окказионализма и контекста отнесены слова, интерпретация которых в меньшей сте- 
пени, чем при других типах, зависит от вербального контекстного окружения. В данной группе окказиональных слов основной является стилистическая функция. В романе «Улисс» Дж. Джойс, «вопреки всей своей поразительной многосторонности, идет за определенной мелодией» [4, с. 121], ведь благодаря богатству своих выразительных средств слово может передавать ритм, гармонию, тембр, «музыкализуя» сам текст [5, с. 87]. Отсюда нередким становится появление огромного количества ономатопеических образований, где поиск семантических ассоциативных связей основывается именно на звуковом образе (to sllt, jiggedy, jing, iddle, oodle, hissss, pwee).

Отсутствие очевидных формально-содержательных связей окказионального слова и контекста, согласно классификации О.Г. Баталова, наблюдается и у морфологически мотивированных единиц. Анализ показал, что в романе «Улисс» данная группа малочисленна, однако представлена рядом примеров (horseness, spanishy, yellowly, outsmile). В случае прозрачной модели словообразования межъязыковая трансляция подобных единиц, как правило, не вызывает больших затруднений и приводит к принятию аналогичных переводческих решению: rerridled - rätselte (Г. Гойерт), rückrätselte (Г. Волльшлегер), озагадочилось (В. Хинкис, С. Хоружий), озагадочилось (С. Махов).

В группе первого типа рассматриваются также окказионализмы, осложненные стилистическими тропами и фигурами. В романе «Улисс» встречаются окказионализмы-метафоры (spoon-seat), окказионализмы-сравнения (cabbagelooking, orangefiery, panama-helmeted, horse-nostrilled), окказионализмы-оксюмороны (nightsun, shybrightly), лексические окказионализмы, функционирующие в составе гиперболы (allhorse (гипербола преувеличивает свойства лошади), oversoul (гипербола преувеличивает качество души), lumpmusic (гипербола преувеличивает масштабы музыки)). Были также обнаружены окказиональные единицы, в основе которых лежит метонимический перенос, связанный, как известно, с законом языковой экономии (azureyed (to look with azure eyes), limblessly (like having no limbs)). Рассмотрим пример переводов окказионализма из первой группы.

The ghost walks, Professor MacHugh murmured softly, biscuitfully, to the dusty windowpane [6, p. 118].

«Das Gespenst geht um», murmellte Professor MacHugh leise, biskuitvoll gegen die staubige Fensterscheibe [7, S. 142].

- Da klingt das Geld im Kasten, murmelte Professor MacHugh leise und biskuitvoll gegen die staubige Fensterscheibe [8, S. 169].

- Входит призрак, - тихонько прошамкал запыленному окну профессор Макхью полным печенья ртом [9, с. 119].

- Входит призрак, - тихонько прошамкал запыленному окну профессор Макхью полным печенья ртом [10, с. 117]. 
Окказионализм buiscuitfully (with mouth full of biscuits) осложнен метонимией и выполняет, прежде всего, стилистическую функцию. Немецкие переводчики транслируют его окказиональной единицей с соблюдением модели словообразования, тогда как в русских переводах присутствуют узуальные лексемы.

В целом из вышеприведенных примеров очевидно, что семантика окказиональных слов первого типа относительно автономна. Для межъязыковой трансляции подобных индивидуально-авторских новообразований, как правило, необходимы языковые знания реципиента (о словообразовательных моделях, формантах и их семантики), хотя в некоторых случаях требуется также учет ситуативных факторов.

К окказионализмам второго типа относят слова, восприятие которых тесно связано с вербальным или вертикальным контекстом. Такие словообразовательные единицы обладают анафорическими и катафорическими формально-содержательными связями с вербальным окружением, а также идентификация их значения может подразумевать активизацию фоновых знаний. Помимо стилистической функции подобные окказионализмы выполняют контекстосвязующую или текстосвязующую функции.

В романе «Улисс» наиболее часто встречаются окказионализмы, главенствующую роль при восприятии которых играет предшествующий текст (наличие анафорической связи). При этом апелляция может происходить как к ближнему, так и к дальнему контексту. Приведем пример окказионального слова, демонстрирующего связь с дальним контекстом, указанным ниже в квадратных скобках, и возможности его перевода.

He looks round, darts forward suddenly. Through rising fog a dragon sandstewer, traveling at caution, slews heavily down upon him, its huge red headlight winking, its trolley hissing on the wire. The motorman bangs his footgong. $<\ldots>$ The brake cracks violently. Bloom, raising a policeman's white-gloved hand, blunders stiff-legged out of the track. The motorman, thrown forward, pugnosed, on the guidewheel, yells as he slides past over chains and keys [6, p. 412]

Might have lost my life too with that mangongwheeltracktrolleyglarejuggernaut only for presence of mind. Can't always save you though [6, p. 424].

Er blickt sich um, saust dann plötzlich weiter. Durch den steigenden Nebel kommt ein drachenhafter Sandsteuer auf ihn zugekrochen; die große, rote Vorderlaterne blinzelt, die Rolle zischt am Draht. Der Wagenführer tritt die Fußglocke. $<\ldots>$ Die Bremse kracht laut. Bloom hebt eine weissbehandschuhte Polizistenhand und stolpert steifbeinig aus dem Geleise. Der klumpnasige Wagenführer, der nach vorn auf das Führerrad geschleudert wurde, schreit, als er über Ketten und Keile rutscht [7, S. 490].

Leben kommen können mit diesem Kerlglockeradgeleiserolleglitschigerboden, wenn ich nicht Geistesgegenwart besessen hätte [7, S. 501]. 
Er blickt sich um, stürmt plötzlich weiter. Durch den steigenden Nebel schwenkt mit warnender Bewegung ein drachengleicher Sandsteuer zu ihm nieder; die riesige rote Kopfla-terne blinkt, die Kippe zischt am Drahtseil. Der Motorführer tritt heftig auf dem Fußgong. < ..> Die Bremse kracht heftig. Bloom hebt eine weißbehandschuhte Polizistenhand und tappt steifbeinig aus dem Geleis. Der Motorführer, stumpfnäsig vorgeschleudert auf das Lenkard, schreit gellend, als er über Ketten und Schalter rutscht [8, S. 592].

Hätte ja auch glatt ums Leben kommen können durch diesen Kerlgongradgleisrolleglitzerdschagannath, wenn ich nicht geistesgegenwärtig genug [8, S. 606].

Оглядевшись по сторонам, резко кидается вперед. В сгущающемся тумане к нему коварно подкрадывается дракон пескоразбрасыватель, он едет на малой скорости, во лбу мигает большая красная фара, с шипеньем и треском искрит дуга. Вожатый жмет на педаль сигнального гонга. <..> Яростно взвизгивают тормоза. Блум, подняв руку в белой полисменской перчатке, торопится унести с рельсов ноги, которые внезапно не слушаются его. Вожатый, едва не налетев на свою баранку курносым носом, окруженный проводами и рычагами, проезжая, орет [9, с. 416].

Мог бы расстаться с жизнью из-за этого трамгонгфардугрельсджаггернаут, хорошо, что не растерялся [9, с. 426].

Оглядевшись, резко мчит вперед. В сгущающемся тумане на него выворачивает туша осторожно ползущего ящера-пескоразбрасывателя, во лбу мигает огромное красное око, шипит по тоководу дуга. Вожатый жмет ногой на рычаг гудка. <..> Яростно клацают тормоза. Блум, подняв руку в белой перчатке блюстителя порядка, с трудом переставляя ватные ноги, освобождает колею. Курносый вожатый, напоровшийся с разлету на баранку, орет, проплывая в окруженьи проводов и кнопок [10, с. 419].

Чуть жизни не решился из-за той вожатогудкоколесопутедугосветодавилки, хорошо сохранил присутствие духа [10, с. 429].

Поскольку стиль Дж. Джойса обладает элементами импрессионизма, при описании происшествия с Блумом автор сначала использует «крупные мазки», т.е. отдельные лексемы, которые затем превращаются в единое окказиональное «слово-монстр» mangongwheeltracktrolleyglarejuggernaut (man + gong + wheel + + track + trolley + glare + juggernaut), созданное им из семи основ. При этом две последние основы употреблены в отрывке впервые (glare - ослепительно светить, juggernaut - в индуистской мифологии огромная давящая колесница).

Как видно из переводов, каждый переводчик по-своему выделил основы окказиональной лексемы Дж. Джойса, а следовательно, семантические компоненты переводных единиц не совпадают. В немецких переводах присутствуют семиосновные окказионализмы, в структуре которых мы видим лишь три (у Г. Гойерта) и два (у Г. Волльшлегера) повторяющихся элемента. Кроме того, лексема Г. Гойерта не содержит культурологическую реалию 
(Джаггернаут), которая заменена нейтральной единицей Boden, а переводное «соответствие» Г. Волльшлегера оканчивается окказиональным новообразованием «schagannath». Оба русских переводчика предложили шестиосновные окказиональные единицы, при этом В. Хинкис, С. Хоружий максимально приблизились к лексеме Дж. Джойса, продублировав в ней 4 основы и оставив культурологическую реалию. С. Махов заменил простое примыкание основ или агглютинацию, использованную Дж. Джойсом, на соединение при помощи морфем, более типичное для русского языка, таким образом пытаясь добиться максимального облегчения восприятия сложной окказиональной единицы русскими читателями.

Реже в тексте романа встречаются окказиональные слова, демонстрирующую катафорическую связь с контекстом, являющуюся исходной точкой развития темы.

She used to say Ben Dollard had a base barreltone voice. He has legs like barrels and you'd think he was singing into a barrel [6, p. 147].

Sie sagte immer, Ben Dollard hätte eine tiefe Fassstimme. Er hat Beine wie Fässer, und man meint, er sänge in ein Fass [7, S. 175].

Sie sagte zum Beispiel immer, Ben Dollard wäre ne Baß-Baritonne. Nun hat er ja Beine wie Fässer, und man könnte tatsächlich meinen, er sänge in eine Tonne [8, S. 208].

Скажем, она придумала, что у Бена Долларда не бас-баритон, а басбормотон. Потому что когда поет, половину звуков глотает и ни слова не разберешь [9, с. 147].

Придумала же дескать у Бена Долларда не бас-баритон, а басбочкотон. Ноги у него вроде бочонков и поет точно в кадушку [10, с. 144].

Каждый переводчик по-своему передает игру слов, в которую вовлекает писатель. В переводе В. Хинкиса, С. Хоружего, однако, не прослеживается указание на зависимость окказионального прозвища певца от формы его ног.

Связь окказиональных единиц с контекстом может быть также анафорическо-катафорической: At Passage was his body laid. Dolor! Oh, he dolores! The voice of the mournful chanter called to dolorous prayer [6, p. 273]. Очевидно, что в этом случае переводчикам также необходимо определить и учесть все контекстосвязующие нити при трансляции окказиональной единицы.

Еще одна группа окказионализмов - это единицы, апеллирующие к фоновым знаниям реципиента (вертикальный контекст). В романе «Улисс» особенно часто встречаются: а) референция к антропонимам (sherlockholmsing, columble, dongiovannism, shakescene); б) референция к топонимам (Hogsnorton, Big Benaben, patsypunjaub, Brutish); c) референция к фразеологизмам и текстам (ticktacktwo wouldyousetashoe, come-to-bed (hat), bird-in-the-hand). Именно такие окказионализмы вызывают особую сложность при трансляции. Основная задача переводчика сохранить окказиональность лексемы, прежде всего за счет по- 
вторения словообразовательной модели, и в то же время передать компонент национально культурной информации (Shelrlockholmsieren, шерлокхолмствовать). Порой сохранение первого ведет к потере второго (Большой Бенабен) или, наоборот (Halt die Klappe, noдите вы к черту), возможна потеря и того и другого (Szenenerschütterer, потрясатель сиены).

Окказионализмы третьего типа поддерживают и организуют динамическое развертывание текстового целого, обеспечивая тем самым его концептуальное единство. Это, как правило, целые окказиональные цепочки, например цепочки окказиональных прилагательных или окказиональных имен собственных. Такие цепочки - не редкость для техники Дж. Джойса и требуют особого внимания со стороны переводчиков: Bloom looked at the head of the horse... it was a fourwalker, a hipshaker, a black-buttocker, a taildangler, a headhanger $<\ldots>$ [6, p. 576]. К особенностям перевода подобных единиц мы обращались в наших более ранних работах [11].

Как известно, обязательными компонентами структуры любой языковой игры являются ядро (два элемента, объединённых или сходной фонетической или графической формой, но различных по содержанию) и базисный контекст, создающий минимальные условия реализации элементов ядра языковой игры $[12$, с. 73]. Лексической составляющей ядра языковой игры Дж. Джойса нередко становятся именно окказиональные единицы. Подход к их передаче должен быть индивидуальным в каждом случае. Переводчику необходимо оценить эмоциональную силу ономатопеической окказиональной единицы и по возможности передать ее внутреннюю форму и образность, что едва ли достижимо при использовании транскрибирования в чистом виде.

Old Mrs Riordan with the rumbling stomach's Skye terrier in the City Arms Hotel. $<\ldots>$ O, the big doggybowwowsywowsy [6, p. 166].

Die alte Frau Riordan mit dem magenknurrenden Skye Terrier im City Arms Hotel. < ..> Oh, du liebes Wauwauwauchen [7, S. 198].

Der alten Mrs. Riordan mit dem knurrenden Magen ihr Skye-Terrier im City Arms Hotel. < ..> Oh, was für ein hübsches großes Wauwauchen [8, S. 237].

В гостинице «Городской герб» у старой миссис Риордан был скайтерьер, у которого вечно бурчало в рюхе. $<\ldots>$ Ax ты собачка, ты мой гавгавгавчик $[9$, с. 166$]$ !

В гостинице «Городской герб» у старой госпожи Райордан жил скайтерьер с вечным бурчаньем в брюхе. $<\ldots>$ Ого-го какой у тебя большой $\partial p y-$ жок-стручок-хомячок [10, с. 164].

При создании звукоподражательного окказионализма doggybowwowsywowsy (doggy + bow + wow + -sy + wow + -sy) задействованы словосложение, редупликация и суффиксация. В немецких версиях романа, а также в первой версии русского перевода окказиональное существительное передано ономатопеической окказиональной единицей, обладающей более прозрачной моделью 
словообразования, чем та, что была использована Дж. Джойсом. Звуковые ассоциации с собачьим лаем не находят место лишь в переводе С. Махова, где окказионализм создан слиянием трех рифмующихся основ.

Итак, отношение окказионального слова и контекста в основном закономерно носит характер взаимодействия. С одной стороны, окказионализмы Дж. Джойса искусно вплетены в ткань произведения, неизбежно организуя его структуру и представляя собой опору, относительно которой осуществляется понимание всего романа в целом. С другой стороны, контекст почти всегда в большей или меньшей степени является фактором, определяющим понимание окказиональной единицы, а следовательно, и его правильной передачи в языке перевода. Значение окказионализма может предусматривать активацию различных связей с вербальным контекстом, а также апелляцию к фоновым знаниям. Применение разных переводческих приемов при передаче одного и того же окказионализма, как правило, объясняется возможностью разнообразных интерпретаций окказионализмов Дж. Джойса, что максимально, как нам кажется, затрудняет работу переводчиков в поиске соответствий на языке перевода. Тем не менее в текстах перевода на обоих языках нередко встречаются удачные примеры транслируемости окказионализмов Дж. Джойса, что свидетельствует о том, что переводчики в целом справляются с «вызовом», брошенным писателем в романе, столь насыщенного сложнейшими авторскими новообразованиями, что их переводимость кажется порой невыполнимой задачей.

\section{Список литературы}

1. Комиссаров В.Н. Лингвистика перевода. - М.: Изд-во ЛКИ, 2007. - 176 с.

2. Гениева Е.Ю. И снова Джойс.... - М.: Изд-во ВГБИЛ им. М.И. Рудомино, 2011. $-368 \mathrm{c}$.

3. Баталов О.Г. Семиотический статус окказионализма и его функции в художественном тексте // Язык, коммуникация и социальная среда. - Воронеж: Изд-во ВГУ, 2004. - Вып. 3. - С. 129-136.

4. Юнг К.Г. Дух в человеке, искусстве и литературе. - Минск: Харвест, 2003.$384 \mathrm{c}$.

5. Rabate Rabaté, J.-M. The silence of Sirens // James Joyce: the centennial symposium.- Chicago: University of Illinois press, 1986. - P. 82-88.

6. Joyce J. Ulysses. - London: Picador, 1998. -741 p.

7. Joyce J. Ulysses: Roman / übersetzt von Georg Goyert. - Zürich: Rhein-Verlag, 1956. $-836 \mathrm{~S}$.

8. Joyce J. Ulysses: Roman / übersetzt von H. Wallschläger. - Frankfurt am Mein: Surkamp Taschenbuch, 2004. $-989 \mathrm{~s}$.

9. Джойс Дж. Улисс: роман / пер. с англ. В. Хинкис, С. Хоружий. - СПб.: Симпозиум, 2002. $-830 \mathrm{c}$.

10. Джойс Дж. Сочинения: в 3 т. Т II: ОдиссейЯ. - М.: СФК Инвест, 2007. - 696 с. 
11. Наугольных Е.А. Окказионализмы как элемент языковой игры писателя // Вестник Пермского университета. Российская и зарубежная филология. - Пермь, 2010. Вып. 6 (12). - С.83-90.

12. Виноградов В.В. Лексические вопросы перевода художественной прозы. М.: Высшая школа, 1978. - 174 с.

\section{References}

1. Komissarov V.N. Lingvistika perevoda [Translation linguistics]. Moscow: Izd-vo LKI, 2007. 176 p.

2. Genieva E.Iu. I snova Dzhois... [And Joyce again...]. Moscow: Izd-vo VGBIL im. M.I. Rudomino, 2011. 368 p.

3. Batalov O.G. Semioticheskii status okkazionalizma i ego funktsii $v$ khudozhestvennom tekste [Semiotic status of occasionalism and its functions in fiction]. Iazyk, kommunikatsiia i sotsial'naia sreda. Voronezh: Izd-vo VGU, 2004, no. 3, pp. 129-136.

4. Iung K.G. Dukh v cheloveke, iskusstve i literature [Spirit in man, art and literature]. Minsk: Kharvest, 2003. 384 p.

5. Rabate Rabaté, J.-M. The silence of Sirens // James Joyce: the centennial symposium. Chicago: University of Illinois press, 1986, pp. 82-88.

6. Joyce J. Ulysses. London: Picador, 1998. 741 p.

7. Joyce J. Ulysses / übersetzt von Georg Goyert. Zürich: Rhein-Verlag, 1956. 836 p.

8. Joyce J. Ulysses / übersetzt von H. Wallschläger. Frankfurt am Mein: Surkamp Taschenbuch, 2004. 989 p.

9. Dzhois Dzh. Uliss: Roman [Ulysses]. Transl. by V. Khinkis, S. Khoruzhii. SaintPetersburg: Simpozium, 2002. 830 p.

10. Dzhois Dzh. Sochineniia: v 3 t. [Selected works]. Part II: OdisseiIa. Moscow: SFK Invest, 2007. 696 p.

11. Naugol'nykh E.A. Okkazionalizmy kak element iazykovoi igry pisatelia [Occasionalisms as elements of the writer's language game]. Vestnik Permskogo universiteta. Rossiiskaia i zarubezhnaia filologiia. Perm', 2010, no. 6 (12), pp. 83-90.

12. Vinogradov V.V. Leksicheskie voprosy perevoda khudozhestvennoi prozy [Lexical issues in fiction translation]. Moscow: Vysshaia shkola, 1978. 174 p.

Получено 12.02.2016

\section{Сведения об авторе}

\section{НАУГОЛЬНЫХ Евгения Андреевна}

e-mail:pulina_jane@mail.ru

кандидат филолологических наук, доцент, доцент кафедры иностранных языков Пермской государственной фармацевтической академии (Пермь, Россия)

\section{About the author}

\section{Evgeniia A. NAUGOLNYKH \\ e-mail:pulina_jane@mail.ru}

Candidate of Philological Sciences, Docent, Associate Professor, Department of Foreign Languages, Perm State Pharmaceutical Academy (Perm, Russia) 